\title{
Controle de qualidade dos extratos polares de Turnera diffusa Willd. ex Schult., Turneraceae
}

\author{
Ely E. S. Camargo, ${ }^{*}, 1,2$ Wagner Vilegas ${ }^{1}$
}

${ }^{1}$ Departamento de Química Orgânica do Instituto de Química, UNESP, Rua Francisco Degni s/n, Bairro Quitandinha, 14800-900 Araraquara -SP, Brasil

${ }^{2}$ Faculdade de Ciências Farmacêuticas, UNESP, Rodovia Araraquara/Jaú, km 1, 14801-902 Araraquara-SP, Brasil.

\begin{abstract}
RESUMO: Este trabalho descreve o desenvolvimento de metodologia para o controle de qualidade dos extratos etanólicos e infusão de Turnera diffusa Willd. ex Schult., Turneraceae, usando como marcadores os compostos fenólicos. Essa espécie é usada popularmente como afrodisíaca e antiulcerogênica. Foram usadas técnicas cromatográficas: CLAE acoplada com detector de ultravioleta e cromatografia em camada delgada. Foram detectados flavonóides como os principais componentes da planta.
\end{abstract}

Unitermos: Turnera diffusa, Turneraceae, controle de qualidade, flavonoides.

\begin{abstract}
Quality control of polar extracts from Turnera diffusa Willd. ex Schult., Turneraceae." This work describes the development of a methodology for the quality control of ethanol and infusion extracts from Turnera diffusa Wild ex Schult., Turneraceae, using phenolic compounds as chemical markers. This species is used both as aphrodisiac and antiulcerogenic. We used chromatographic techniques: HPLC couplet do ultraviolet detector as well as thin layer chromatography. Flavonoids were detected as major compounds in this species.
\end{abstract}

Keywords: Turnera diffusa, Turneraceae, quality control, flavonoids.

\section{INTRODUÇÃO}

A Turnera diffusa Willd. ex Schult., Turneraceae, é um arbusto aromático perene, caracterizado por apresentar uma altura máxima de $2 \mathrm{~m}$, folhas simples pecioladas e lanceoladas, com aproximadamente $2,5 \mathrm{~cm}$ de comprimento, coloração verde amarelada, apresentando na parte inferior venação saliente. Suas flores são pequenas, axilares, amarelas, que aparecem no final do verão e são seguidas por um fruto capitular, globoso e pequeno que contém numerosas sementes (Alonso, 1998). Turnera difusa é uma planta predominantemente de regiões áridas e semi-áridas, que se estende desde a Califórnia e México até América do Sul. Também é encontrada na Índia (AlcarazMeléndes et al., 1994).

Na família Turneraceae são encontradas espécies com importância medicinal. No México e em Cuba, os índios usam o extrato aquoso de Turnera difusa como expectorante, diurético, afrodisíaco e em outros tratamentos (Perez et al., 1984). O decoto de folhas de $T$. difusa também é usado para curar distúrbios digestivos (Krag, 1976; Ishikura, 1982). Na Bolívia, o extrato aquoso das folhas é usado no tratamento da blenorragia. O chá de T. ulmifolia, preparado usando-se a planta inteira, é indicado para mulheres em período pós-parto e para aquelas que apresentam amenorréia (Ayensu, 1978). Em Cuba, o extrato aquoso a quente das flores é utilizado para alívio das cólicas menstruais. Na Jamaica, o extrato aquoso das folhas é utilizado como antipirético e na Colômbia o decoto das folhas é usado como abortivo.

Atualmente, as farmácias de manipulação, por não disporem de equipamentos para moagem e na maioria dos casos não terem espaço físico em seus estabelecimentos, adquirem as drogas vegetais já pulverizadas no comércio, ficando difícil a identificação botânica e na maioria das vezes adquirem as plantas de fornecedores não idôneos, atraídos por custos bem menores dos praticados no mercado. A identificação, neste caso, é difícil, pois seria necessário um controle químico, o que implicaria em estabelecer uma quarentena para o uso da droga, uma vez que os estabelecimentos trabalham com estoques mínimos. Portanto, não tem noção do que está sendo adquirido, onde pode-se observar na substituição da Turnera diffusa, pouco encontrada no Brasil, com a Turnera ulmifolia, bastante difundida em todo território brasileiro . Em virtude dessas dificuldades de identificação, em grande parte por falta de monografias de controle da qualidade, acabam levando as pessoas consumirem fitoterápicos erradamente, o que pode ocasionar supressão de efeitos ou mesmo apresentando efeitos indesejáveis e até tóxicos. 
A legislação atual que regulamenta o registro e comercialização de fitoterápicos no Brasil, foi publicada em março de 2004 pela Anvisa, a qual revogou as portarias números 123 e 6 do SNVS/MS e RDC 17 Anvisa, apresenta como exigências o controle botânico, controle microbiológico e o controle químico de qualidade, além da exigência de ensaios pré-clínicos e clínicos da droga. Para estes últimos a ANVISA estabeleceu um prazo para os fabricantes comprovarem eficácia clínica (Anvisa, 2004). Porém, em 2009, através de consulta pública a câmara técnica de fitoterápicos da Anvisa definiu novas regras para registros de produtos fitoterápicos baseados no uso popular da planta medicinal, a qual deverá apresentar através de relatos e depoimentos seu uso nos últimos 20 anos, caracterizando os efeitos terapêuticos e não toxicidade observada.

Apesar das exigências implícitas na legislação vigente, pode-se observar que algumas empresas brasileiras não têm se preocupado em garantir a qualidade dos produtos fitoterápicos. Vale ressaltar que desde de dezembro de 1993 a Organização Mundial de Saúde, através de um relatório, expõe a importância do controle de qualidade de fitoterápicos, visando uma preocupação com a saúde da população mundial.

\section{MATERIAIS E MÉTODOS}

\section{Material botânico}

As plantas utilizadas foram fornecidas pelo Departamento de Fisiologia do Instituto de Biociências da Unicamp, provenientes de Quintana Roo, México, onde foram identificadas macro e microscopicamente, depositada no herbário do Centro de Investigação Científica de Yucatan sob número 3773. Os extratos foram preparados por maceração a partir das folhas secas e moídas de $T$. diffusa em etanol (EtOH 96\%) por sete dias, após filtrou-se e concentrou-se em evaporador rotativo a $50{ }^{\circ} \mathrm{C}$ até completa evaporação do EtOH 96\% (Poser \& Mentz, 2004).

\section{Análises cromatográficas}

Os experimentos foram feitos em cromatógrafo Waters modelo Millipore, equipado com sistema binário de bombas modelo 501 Waters, detector UV (Waters modelo 486), coluna Phenomenex C-18 em fase reversa $(250 \times 4,60 \mathrm{~mm}, 5 \mu)$. As condições cromatográficas foram estabelecidas após experimentos realizados com diversos sistemas de solventes, sendo que, na quantificação da apigenina-7- $O$ - $\beta$-D- $p$-coumaroil $(1 \rightarrow 6)$ glucopiranosídeo (1) foi por modo gradiente com acetonitrila/água e ácido fórmico $0,5 \%$. A mistura foi estabelecida, iniciando-se com uma concentração de $30 \%$ de acetonitrila e $70 \%$ de água/ácido fórmico, aumentando-se progressivamente a concentração de acetonitrila até $40 \%$ em um período de
40 min, passando a $100 \%$ em 5 min, permanecendo nessa concentração por mais $20 \mathrm{~min}$. $\mathrm{O}$ sistema de solventes utilizados na quantificação da $p$-arbutina (2), foi por modo gradiente com metanol/água, inicialmente com uma concentração de metanol $10 \%$, passando a $50 \%$ em 30 min, na seqüência elevou-se a concentração de $\mathrm{MeOH}$ para $100 \%$, permanecendo assim por aproximadamente 20 min (Collins, 1977).

Nas análises por cromatografia comparativa em camada delgada (CCCD), na identificação de $p$-arbutina presente somente nos extratos etanólico e infusão de $T$. diffusa, utilizou-se placas, as quais foram preparadas aplicando-se uma suspensão de silica gel 60 (Merck) em água destilada, na proporção $1: 2(\mathrm{p} / \mathrm{v})$, sobre placas de vidro $5 \times 10$ ou $20 \times 10 \mathrm{~cm}$, obtendo-se $0,25 \mathrm{~mm}$ de espessura de adsorvente. Após a preparação das placas, as mesmas foram deixadas em repouso por aproximadamente $8 \mathrm{~h}$ à temperatura ambiente e após a secagem, foram colocadas em estufa a $120^{\circ} \mathrm{C}$ por um período de 30 min para ativação (Collins, 1977).

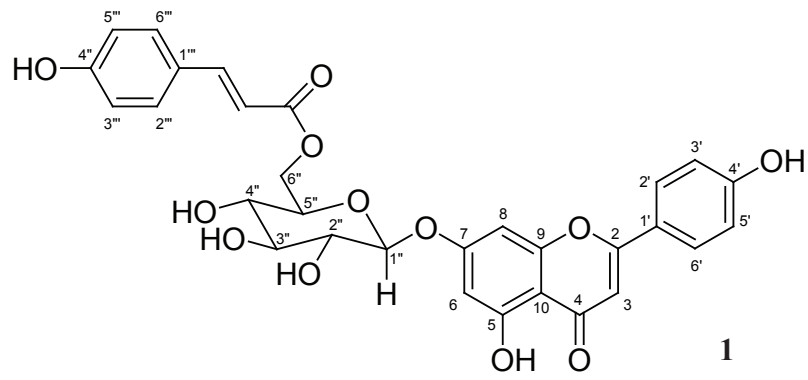<smiles>OCC1OC(O)C2(CO)C(O)C1C(O)C2Oc1ccc(O)cc1</smiles>

\section{Determinação de cinzas}

No desenvolvimento da análise de cinzas totais foram tomados $3,0 \mathrm{~g}$ de folhas secas e moídas de $T$. diffusa e T. ulmifolia, em cadinho previamente calcinado, resfriado e pesado. As amostras foram inicineradas até a eliminação de todo o carvão. Após resfriamento em dessecador, aquilatou-se a massa do conjunto. $\mathrm{Na}$ determinação de cinzas insolúveis em ácido o resíduo obtido na determinação de cinzas totais foi fervido por 5 min com $25 \mathrm{~mL}$ de $\mathrm{HCl}$, em cadinho coberto com vidro de relógio. Lavou-se o vidro de relógio com $5 \mathrm{~mL}$ de água quente, juntando a água ao cadinho. Recolheu-se o 
resíduo insolúvel sobre papel de filtro isento de cinzas, lavou-se com água quente até neutralização do filtrado, transferiu-se o papel contendo o resíduo para um cadinho seco e incinerou-se, sendo a massa determinada ao final do processo (F. Bras IV, 1988).

\section{Doseamento de flavonóides totais}

Na determinação de flavonóides totais, colocouse em um balão de fundo redondo de $100 \mathrm{~mL}, 0,4 \mathrm{~g}$ da droga moída com granulometria 1-0,8 mm, exatamente pesados, acrescidos de $1 \mathrm{~mL}$ de uma solução de urotropina (hexametilenotetramina) a $0,5 \%, 20 \mathrm{~mL}$ de acetona $\mathrm{R}$ e 2 $\mathrm{mL}$ de ácido clorídrico R e aqueceu-se em manta, mantendo sob refluxo, por $30 \mathrm{~min}$. Filtrou-se através de uma pequena quantidade de algodão para um balão volumétrico de 100 mL. Lavou-se o resíduo da droga e o algodão, em balão de fundo redondo, com duas porções de $20 \mathrm{~mL}$ de acetona, sob refluxo, por $10 \mathrm{~min}$. Após arrefecimento a temperatura ambiente, as soluções foram filtradas, através de algodão para um balão volumétrico, completando-se o volume com acetona. Em funil de separação, foi adicionado $20 \mathrm{~mL}$ da solução acetônica, $20 \mathrm{~mL}$ de água destilada. A extração foi realizada com $15 \mathrm{~mL}$ de acetato de etila $\mathrm{R}$, repetindo-se por três vezes, com porções de $10 \mathrm{~mL}$. As frações de acetato de etila foram reunidas e lavadas em funil de separação com duas porções de $50 \mathrm{~mL}$ de água destilada e colocadas em balão volumétrico de $50 \mathrm{~mL}$, completando-se o volume com acetato de etila (solução mãe - SM). Foi adicionado 1 $\mathrm{mL}$ do reagente de cloreto de alumínio (colocou-se 1,0 g de $\mathrm{AlCl}_{3}$ em um balão volumétrico de $50 \mathrm{~mL}$, completandose o volume com solução metanólica de ácido acético a 98 \%) a $10 \mathrm{~mL}$ da solução mãe, diluindo-se a $25 \mathrm{~mL}$ com solução metanólica de ácido acético $\mathrm{R}$ (colocou-se $5 \mathrm{~mL}$ de ácido $98 \%$ em um balão volumétrico de $100 \mathrm{~mL}$, o qual se completa o volume com metanol), obtendo-se assim a solução amostra - SA. Ao mesmo tempo, $10 \mathrm{~mL}$ da solução mãe foram diluídas a $25 \mathrm{~mL}$ com solução metanólica de ácido acético R (solução comparativa - SC). Após 30 min mediu-se a absorvância de SA a $425 \mathrm{~nm}$, em cubeta com 1 $\mathrm{cm}$ de espessura contra SC (Camargo, 2001).

O cálculo do teor baseia-se na absorvância específica da quercetina, $\mathrm{E}^{1 \%}{ }_{1 \mathrm{~cm}}=500$, segundo a fórmula:

$$
Q=\frac{A b s .6250}{500 e \cdot(100-t)}
$$

onde:

Abs = absorvância medida;

$e=$ massa da droga em g;

$\mathrm{t}=$ perda por dessecação $(\% ; \mathrm{m} / \mathrm{m})$.

\section{RESULTADOS E DISCUSSÃO}

A análise quantitativa da apigenina-7-O- $\beta$-D$p$-coumaroil $(1 \rightarrow 6)$ glucopiranosideo (1) foi realizada utilizando-se o método do padrão externo. Foram preparadas soluções-padrão da substância, isolada do extrato EtOH 96\% e identificada por $\mathrm{RMN}{ }^{1} \mathrm{H},{ }^{13} \mathrm{C}$ (Harborne \& Williams, 2000), e massas (Stobiecki, 2000), nas seguintes concentrações: $0,66,2,0$ e $6,0 \mu \mathrm{g} / \mathrm{mL}$. O preparo da amostra se deu a partir do extrato EtOH 96\%, onde coletou-se $100 \mathrm{mg}$ do mesmo e diluiu-se em $1 \mathrm{~mL}$ de metanol. A infusão foi preparada a $10 \%(\mathrm{p} / \mathrm{v})$ da planta seca em água destilada fervente até arrefecimento.

$\mathrm{Na}$ construção da curva de calibração da apigenina-7-O- $\beta$-D-p-coumaroil $(1 \rightarrow 6)$ glucopiranosideo foi encontrado um valor de índice de correlação de 0,99959 . O cromatograma mostra a separação dos componentes presentes no extrato EtOH $96 \%$ de T. diffusa. Pode-se perceber que a separação dos componentes foi obtida em aproximadamente $40 \mathrm{~min}$, obtendo-se boa resolução cromatográfica dos picos. $\mathrm{O}$ pico correspondente à substância apigenina-7-O- $\beta$-D- $p$-coumaroil $\quad(1 \rightarrow 6)$ glucopiranosideo elui com tempo de retenção $23,37 \mathrm{~min}$, (Figura 1) o que foi comprovado pelo enriquecimento do extrato pela adição do mesmo composto, isolado pelos procedimentos fitoquímicos. Esse pico apresentou boa resolução de linha base, de forma a permitir não só o controle qualitativo, mas também quantitativo da substância presente no extrato EtOH 96\% e na infusão das folhas secas e moídas de Turnera diffusa.

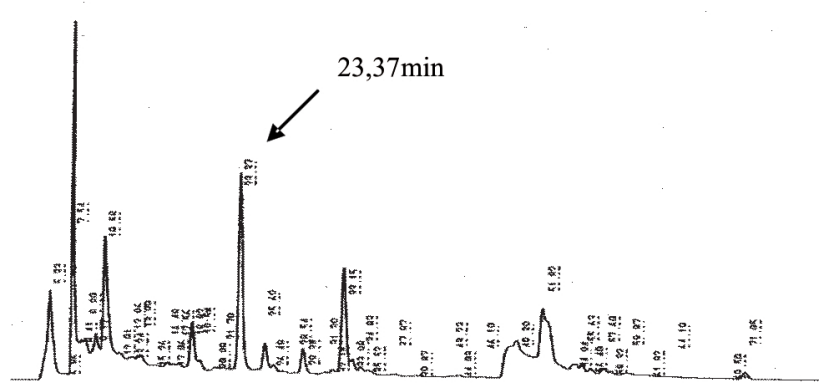

Figura 1. Cromatograma do extrato EtOH 96\% de Turnera diffusa, obtido por HPLC/UV para quantificação da apigenina-7$O$ - $\beta$-D-p-coumaroil $(1 \rightarrow 6)$ glucopiranosídeo $(\mathbf{1})$.

Os resultados foram obtidos através da equação por regressão linear, conseguidos pelo cálculo das áreas, de diversas concentrações diferentes do pico correspondente à apigenina-7- $O$ - $\beta$-D- $p$-coumaroil $(1 \rightarrow 6)$ glucopiranosideo, onde, após identificação e cálculo da média das áreas obtidas determinou-se a concentração da substância em análise, no extrato EtOH 96\%, obtendo $4,4 \mu \mathrm{g} / \mathrm{mL}$ e na infusão a concentração de $1,4 \mu \mathrm{g} / \mathrm{mL}$.

$\mathrm{Na}$ análise quantitativa da $p$-arbutina (2), no extrato EtOH 96\% e infusão das folhas secas e moídas, 
observou-se que o pico correspondente a substância, identificada no cromatograma por injeção direta do padrão externo e confirmado por enriquecimento do extrato EtOH $96 \%$ e da infusão de T. diffusa adicionando 100 $\mu \mathrm{L}$ do padrão externo, em diluição $1: 100$. Verificou-se que o tempo de retenção foi bastante baixo, próximo ao front do solvente, devido à alta polaridade da molécula (Stobiecki, 2000). Mesmo assim considerou-se o melhor sistema de solventes para quantificação da $p$-arbutina no extrato e infusão de $T$. diffusa. Nas condições descritas anteriormente, a $p$-arbutina (2) elui com TR $=11,34$. Dessa forma aquilatou-se a massa a partir do cálculo médio da área do pico correspondente, aplicado a equação obtida pela curva de calibração por regressão linear com uso de padrão externo onde foi determinada a concentração da substância $p$-arbutina na extrato EtOH $96 \%$, obtendo 1,0 $\mu \mathrm{g} / \mathrm{mL}$ e na infusão a concentração de $1,2 \mu \mathrm{g} / \mathrm{mL}$.

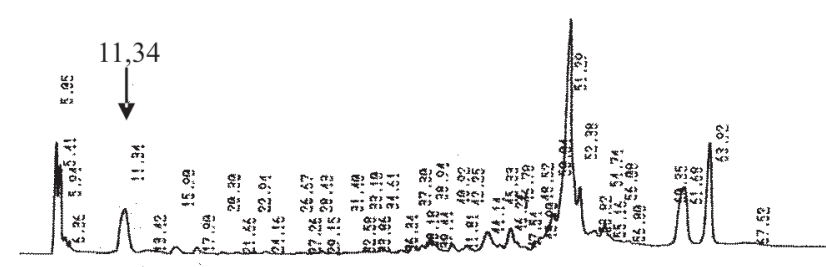

Figura 2. Cromatograma do extrato EtOH $96 \%$ de Turnera diffusa, obtido por HPLC/UV para quantificação da $p$-arbutina (2).

A maneira mais precisa e exata de se identificar e quantificar flavonóides em produtos naturais é a análise por cromatografia líquida de alta eficiência, como apresentado acima. Entretanto, quando se pensa em controle de qualidade, é conveniente a introdução de alternativas mais simples e baratas, pois nesses casos requerem-se procedimentos que permitem a análise rápida de numerosas amostras, em laboratórios modestos. Uma das técnicas que se enquadram bem nesse contexto é a determinação de flavonóides totais por espectrometria no UV.

O método se baseia no uso de cloreto de alumínio, onde se observa a formação de complexo envolvendo o cátion alumínio com os flavonóides em metanol, ocorrendo na análise espectrofotométrica um desvio para maiores comprimentos de onda e uma intensificação da absorção. Dessa maneira é possível determinar a quantidade de flavonóides, evitando-se a interferência de outras substâncias fenólicas, principalmente os ácidos fenólicos, que invariavelmente acompanha os flavonóides. Sendo assim, o complexo flavonóide-Al absorve em comprimento de onda bem maior do que o flavonóide sem a presença do agente complexante.

Na quantificação de flavonóides totais de T. diffusa e T. ulmifólia, pelo método da formação de complexo com cloreto de alumínio, obteve-se, respectivamente $0,33 \%$ e $0,12 \%$, o que claramente evidencia uma diferença significativa. Entretanto, esses resultados corroboram para validação do método de quantificação de flavonóides totais, no controle de qualidade das espécies estudadas nesse trabalho (Falkenberg, 2004).

Muito se fala em variação química e diversidade de substâncias do mesmo gênero, sendo assim um fator importantíssimo na identificação química entre espécies vegetais do mesmo gênero. Sabendo-se que as farmácias adquirem as plantas na forma pulverizadas, avaliou-se a possibilidade de se usar métodos farmacognósticos para melhor elucidar a identificação da espécie.

Um método fácil e prático usado na diferenciação das espécies T. ulmifolia e T. diffusa, que pode ser facilmente realizado em farmácias, é a cromatografia em camada delgada analítica na análise da infusão, para estabelecer a presença de p-arbutina (2), substância esta somente encontrada na espécie $T$. diffusa, podendo, portanto ser usada como marcador para a espécie.

$\mathrm{Na}$ otimização do sistema de solventes que melhor caracteriza a $p$-arbutina na infusão, foi conseguido após várias tentativas, chegou-se à otimização empregando placas de sílica gel (60G Merck) usando como eluente BAW e revelação com vapores de iodo. A $p$-arbutina apresenta $\mathrm{Rf}=0,6$ nessas condições, e pode ser verificada sua presença no infuso das folhas de T. diffusa. É importante salientar que análise similar efetuada com as folhas de $T$. ulmifolia não revelou a presença de p-arbutina, permitindo diferenciar as duas espécies. Dessa forma, a identificação de Turnera diffusa pode ser simplificada, usando padrão externo de p-arbutina, que é facilmente encontrado no mercado.

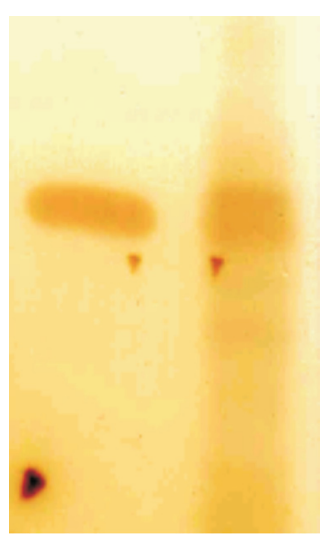

Figura 3. Análise por CCCD do padrão de $p$-arbutina (A) em infusão (B) de Turnera diffusa.

Outro importante requisito na identificação das duas espécies é o índice de cinzas totais e cinzas insolúveis em ácido, os quais permitem diferenciar as espécies, pois nitidamente observamos que o índice de cinza total e insolúvel em ácido são significativamente maiores para a Turnera diffusa em relação a Turnera ulmifolia, conforme resultados apresentados na Tabela 1. Com isso fica evidente que o teste permite de forma rápida a caracterização da espécie adquirida no mercado. 
Tabela 1. Resultados obtidos por determinação de cinzas totais e insolúveis em ácido das espécies Turnera ulmifilia e Turnera diffusa.

\begin{tabular}{lcc}
\hline & $\begin{array}{c}\text { Cinzas insolúveis } \\
\text { em ácido (\%) }\end{array}$ & Cinzas totais (\%) \\
\hline Turnera ullmifolia & 0,12 & 0,75 \\
Turnera diffusa & 2,30 & 6,67 \\
\hline
\end{tabular}

\section{CONCLUSÕES}

Na quantificação dos compostos: apigenina-7- $O$ $\beta$-D-p-coumaroil $(1 \rightarrow 6)$ glucopiranosideo (1) e $p$-arbutina (2), nos extratos EtOH 96\% e infusão, observou-se que a substância (1) apresentou concentração maior no extrato etanólico que na infusão, porém a substância (2) apresentou-se inversamente no extrato e na infusão, o que pode-se caracterizar a alta polaridade do composto (2) em relação ao solvente usado na extração.

Os testes farmacognósticos apresentados no trabalho demonstraram índices confiáveis para determinação qualitativa das espécies, garantindo a identificação segura da Turnera diffusa, Wild.

Assim, pode-se concluir que o conjunto de experimentos realizados nesse trabalho indicaram a que os resultados obtidos podem ser adequadamente empregados para a realização de ensaios de controle de qualidade de Turnera diffusa Willd., Turneraceae.

\section{REFERÊNCIAS}

Alcaraz-MeléndezL, Real-Cosío S, BashanY 1994.Domestication of micropropagated plants of the spice damiana (Turnera diffusa), Plant Cell Rep 13: 679-682.

Alonso JR 1998. Tratado de fitomedicina - Bases clinicas y farmacológicas. Isis Ediciones S.R.L. Buenos Aires, $1039 \mathrm{p}$.

Anvisa 2000. Resolução-RDC n ${ }^{\circ} 17$ de 24.2.2000. Dispõe sobre o registro de medicamentos fitoterápicos. Diário Oficial da União 25.2.2000.

Anvisa 2004. Resolução-RDC no 48 de 16.3.2004. Dispõe sobre o registro de medicamentos fitoterápicos. Diário Oficial da União 18.3.2004.

Ayensu ES 1978. Medicinal plants from West Indies. Manuscript, $110 \mathrm{p}$.

Camargo EES 2001. Perfil químico e controle de qualidade de Turnera diffusa. Dissertação de mestrado, Faculdade de Ciências Farmacêuticas, Universidade Estadual Paulista. Araraquara, $103 \mathrm{p}$.

Collins CH, Braga GL, Bonato PS 1977. Introdução a Métodos Cromatográficos. Campinas Unicamp, $7^{\mathrm{a}}$ edição.

Farmacopéia Brasileira 1988. 4 ed. São Paulo. Atheneu.

Falkenberg MB 2004. Introdução a análise fitoquímica. In: Simões CMO, Schenkel EP, Gosmann G, Mello JCP, Mentz LA, Petrovick PR. Farmacognosia - da planta ao medicamento. $5^{\text {a }}$ ed. Porto Alegre/Florianópolis: UFRGS/UFSC, p. 229-246.

Harborne JB, Williams CA 2000. Advances in flavonoid research since 1992. Phytochemistry 55: 481-504.
Ishikura N 1982. Flavonol glycosides in the flowers of Hibiscus mutabilis v. versicolor. Agr Bio Chem Tokyo 46: 17051706.

Krag KJ 1976. Plants used as contraceptives by North-American indians. An etnobotanical study. Thesis BS, Harvard University, $117 \mathrm{p}$.

Ministério da Saúde 1994. Secretaria de Vigilância Sanitária. Portaria SVS n ${ }^{\circ} 123$ de 19.10.94. Estabelece normas para o registro de produtos fitoterápicos, determinando 30 dias para os questionamentos fundamentados visando o seu aperfeiçoamento. Diário Oficial da União 20.10. 1994.

Ministério da Saúde 1995. Secretaria de Vigilância Sanitária. Portaria SVS n 6 de 31.1.95. Institui e normatiza o registro de produtos fitoterápicos. Diário Oficial da União 6.2.1995.

Perez RM, Ocegueda GA, Munoz JL, Avila JG, Morrow WW 1984. A study of the hypoglycemic effect of some Mexican plants. J Etnopharmacol 123: 253-262.

Poser GLV, Mentz LA 2004. Diversidade biológica e sistemas de classificação. In: Simões CMO, Schenkel EP, Gosmann G, Mello JCP, Mentz LA, Petrovick PR. Farmacognosia - da planta ao medicamento. $5^{\text {a. }}$ ed. Porto Alegre/ Florianópolis: UFRGS/UFSC, p. 75-90.

Stobiecki, M. 2000. Application of mass spectrometry for identification and strutural studies of flavonoid glycosides. Phytochemistry 54: 237-56. 